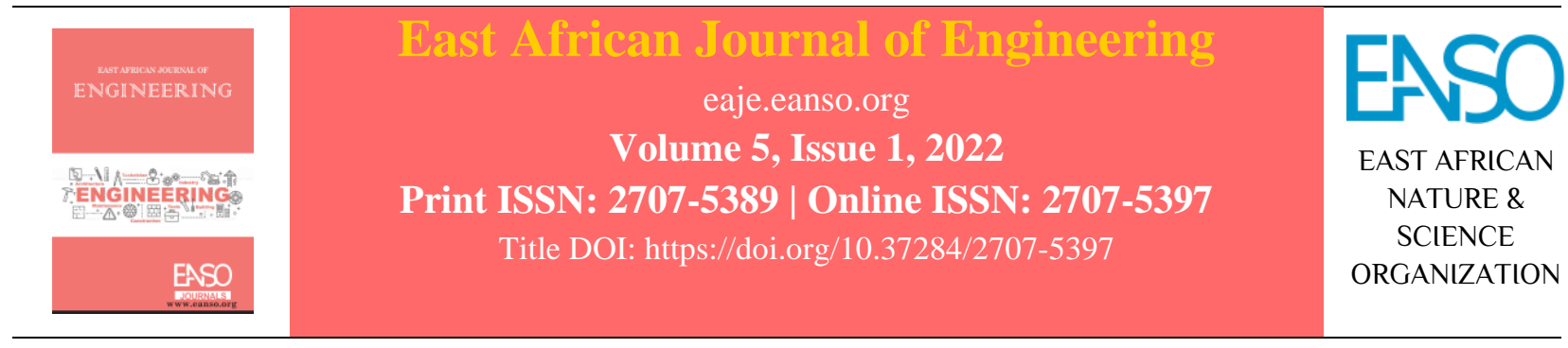

Original Article

\title{
Removal of Acid Red 88 from an Aqueous Solution Using Kaolinite Clay by Adsorption Process.
}

\author{
Derrick Dadebo ${ }^{1 *} \&$ Denis Obura ${ }^{1}$ \\ ${ }^{1}$ Egypt-Japan University of Science and Technology, P. O. Box 179, Alexandria 21934, Egypt. \\ ${ }^{2}$ Pan African University, Tlemcen, Algeria. \\ * Author for Correspondence ORCID: https://orcid.org/0000-0002-0768-1617; Email: derrick.dadebo@ejust.edu.eg.
}

Article DOI: https://doi.org/10.37284/eaje.5.1.561

\section{Publication Date: ABSTRACT}

22 February 2022 Dyes are hazardous contaminants normally found in industrial wastewaters necessitating costly and complex technologies for their removal. In this study, clay

Keywords: was used as an adsorbent in the removal of anionic acid red 88 (AR 88) dye from industrial wastewaters by adsorption. The dye removal efficiency and adsorption capacity of clay was studied by batch experimentation with respect to parameters of dye initial concentration, clay dosage, contact time, and $\mathrm{pH}$. The dye removal efficiency of AR 88 improved with increasing dosage ( $\mathrm{r} 0.9826, \mathrm{p}<0.05)$, contact time ( $\mathrm{r} 0.9821, \mathrm{p} 0.000683$ ) and decreased with increasing initial concentration ( $\mathrm{r}$ - 0.9168, p 0.02844) and pH (r -0.9666, p 0.007297) of the solution. At initial AR dye concentration of $100 \mathrm{mg} / \mathrm{L}$, the removal efficiency and adsorption capacity of $89.7 \%$ and $4.38 \mathrm{mg} / \mathrm{g}$, respectively were achieved after equilibrium time of 30 minutes under the optimum conditions of $\mathrm{pH} 2$ and clay dosage $20 \mathrm{~g} / \mathrm{L}$. The study thrived in applying an efficient and low-cost adsorbent that could be used as a substitute to high-cost conventional commercial adsorbents in treating industrial wastewater with AR dye coloration.

\section{APA CITATION}

Dadebo, D., \& Obura, D. (2022). Removal of Acid Red 88 from an Aqueous Solution Using Kaolinite Clay by Adsorption Process East African Journal of Engineering, 5(1), 57-71. https://doi.org/10.37284/eaje.5.1.561

\section{CHICAGO CITATION}

Dadebo, Derrick \& Denis Obura. 2022. "Removal of Acid Red 88 from an Aqueous Solution Using Kaolinite Clay by Adsorption Process". East African Journal of Engineering 5 (1), 57-71. https://doi.org/10.37284/eaje.5.1.561.

\section{HARVARD CITATION}

Dadebo, D., Obura, D. (2022) "Removal of Acid Red 88 from an Aqueous Solution Using Kaolinite Clay by Adsorption Process", East African Journal of Engineering, 5(1), pp. 57-71. doi: 10.37284/eaje.5.1.561.

\section{IEEE CITATION}

D., Dadebo., \& D. Obura. "Removal of Acid Red 88 from an Aqueous Solution Using Kaolinite Clay by Adsorption Process," EAJE, vol. 5, no. 1, pp. 57-71, Feb. 2022.

57 This work is licensed under a Creative Commons Attribution 4.0 International License. 
Dadebo, Derrick \& Denis Obura. "Removal of Acid Red 88 from an Aqueous Solution Using Kaolinite Clay by Adsorption Process.” East African Journal of Engineering, Vol. 5, no. 1, Feb. 2021, pp. 57-71, doi:10.37284/eaje.5.1.561.

\section{INTRODUCTION}

There is a continuous growth of textile, food, cosmetics, paper, plastics, printing, medicine, and other industries that demand the colouring of their products. At present, there are over 9000 dyes types included in the colour index for various chemical applications in the colouring industries (Q. Wang et al., 2020). Acid red 88 (AR88) is a synthetic anionic red azo dye commonly employed by textile and other industries associated with colouring their products (Abdi et al., 2019). This huge consumption of these synthetic dyes and water by industries as their main raw materials results into a high pollutant load for produced effluents. The discharge of these industrial dye effluent into the environment is associated with environmental pollution like endangering of aquatic life and ecosystem and deterioration of the quality of water (Yusof et al., 2020).

Similarly, these synthetic dyes threaten human health, for example, they are mutagenic, carcinogenic, and poisonous(Thirumoorthy \& Krishna, 2020; Q. Wang et al., 2020). Additionally, undesirable colour changes caused by these dyes of industrial effluent can impede sunlight dispersion into fresh water bodies, dissolved oxygen depletion in the water resulting into hinderance to photosynthetic activities by aquatic plants (Mcyotto et al., 2021). Hence, it is absolutely necessary to remove these dyes from industrial wastewater before being discharged into the environment.

Current treatment methods for removing dyes from industrial wastewater are miscellaneous and include biological, chemical, and physical techniques. Among the widely used methods include; adsorption (Melnyk et al., 2021; Q. Wang et al., 2020; Yusof et al., 2020) photocatalytic oxidation (Badvi \& Javanbakht, 2021; Chaker et al., 2021; S. Wang et al., 2020), coagulation (Feng et al., 2021;
Mcyotto et al., 2021), membrane technologies (H. Liu et al., 2020; Semiz, 2020), biodegradation (Paz et al., 2017; Shoukat et al., 2019), ion exchange(Joseph et al., 2020), and electrochemical methods (Afanga et al., 2020; J. Wang et al., 2020). Different hybrid systems of activated sludge, electrochemical oxidation coagulation, and other treatment methods have also similarly proven high efficiency in the treatment of dye industrial wastewater (Gholizadeh et al., 2020; Mukhlish et al., 2020; Saad et al., 2020; Y. Wang et al., 2020). Due to limitations of these treatment methods in terms of high cost and difficulty in operation, adsorption emerges to be the most suitable treatment method for dye effluents due to its effectiveness in removing different types of pollutants, simple design, and low operating costs associated with it.

Several low cost and readily available adsorbents on the market like rice husk (Bhatti et al., 2020), rice straw (Q. Liu et al., 2020), Zea mays cob (Singh et al., 2017), fish scales (Kabir et al., 2019), orange peels (AbdurRahman et al., 2013), chitosan (Sarkar et al., 2012), activated carbon (Kuang et al., 2020), sawdust (Suganya et al., 2017), carboxymethylcellulose-clay composite (Sirajudheen et al., 2020), sand (Sharma et al., 2019), citrus Limetta Peel (Singh et al., 2017), juncus effusus (Xia et al., 2020), carbohydrate polymeric adsorbent of rice flour (RF) ( Munjur et al., 2020), carbohydrate polymeric adsorbent of wheat flour (WF) (Hasan et al., 2021), graphene Oxide (Almoisheer et al., 2019), and starch-based nanocomposites (Li et al., 2020), have been applied in the removal of dye from industrial wastewater. However, it is crucial to identify a reliable and lowcost alternative adsorbent for sustainable adsorption treatment of industrial dye wastewater.

Clay is a phyllosilicate material located in most parts of Egypt, it has a wide range of applications 
due to its physicochemical properties such as ion exchange capabilities, high surface area, and consequently they are used for adsorption of dyes (Belachew \& Bekele, 2020). Natural clays are gaining importance as low-cost adsorbents because of their abundant availability, easy accessibility and high adsorption capabilities for polar molecules and cations. The net negative charges on clay facilitate the adsorption of basic dyes from aqueous solutions (Akar \& Uysal, 2010). Natural clays exhibit a negative structure charge, which facilitates it to adsorb positively charged dyes but induce a low adsorption capacity for anionic dyes (Dikmen et al., 2015). For instance, Belachew and Bekele (2020) applied bentonite clay in the enhanced adsorption of Congo red dye from an aqueous solution and achieved up to $94.9 \%$ percentage removal. Similarly, Khan (2020) assessed the potential of natural Saudi red clay on the removal of methylene blue dye from aqueous solution by adsorption and results showed that it could achieve up to $95 \%$ removal.

In the present study, clay has been assessed as an environmentally friendly and economically feasible adsorbent in removing acid red 88(AR 88) dye from an aqueous solution by the adsorption method. The adsorption of acid red 88 was investigated under batch mode adsorption and the effects of factors; adsorbent dose, $\mathrm{pH}$, initial dye concentration, and contact time were investigated. The performance of clay as an adsorbent has been compared with other reported works.

\section{METHODOLOGICAL APPROACH}

This section entails the methodological approach and materials adopted in this research as adsorbents and adsorbate, their procedure of preparation and steps for conducting adsorption batch experiments (see Figure 1 below) as well as the adopted analytical methods in the study.

Figure 1: Steps for conducting adsorption batch experiments

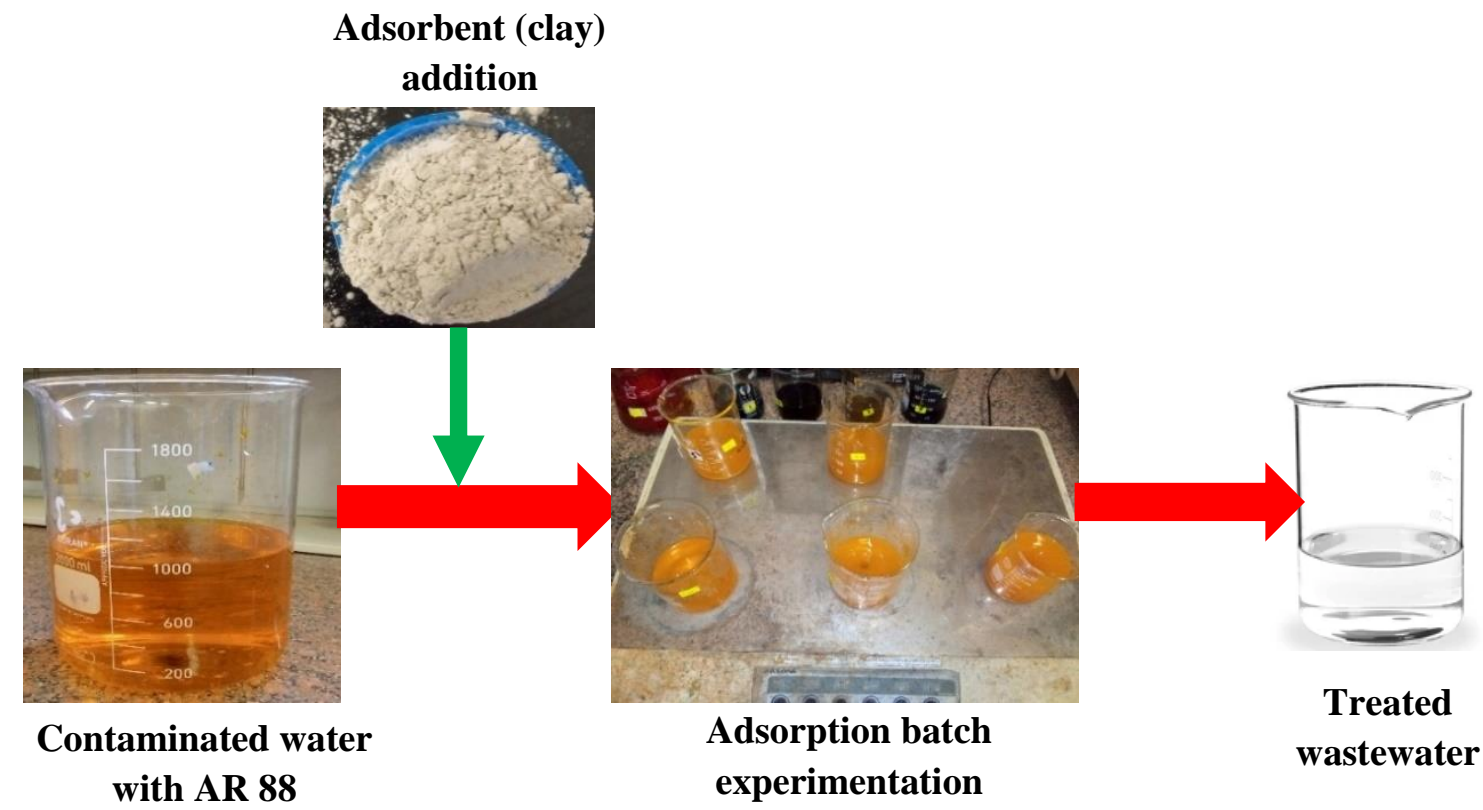

\section{Materials and Chemicals}

Clay was used in this study as obtained in its raw form without any chemical or physical made modification on it. All reagents used were analytical grade and were not subjected to any additional form of modification. Acid red (AR) 88 dye was obtained

59 | This work is licensed under a Creative Commons Attribution 4.0 International License. 
from a dye manufacturing company in Borg Arab Alexandria. Distilled water was used to prepare all aqueous solutions in the study. Clay was acquired from a ceramic factory in Borg Arab, Alexandria, Egypt.

\section{Adsorbent Sample}

The adsorbent used in this study was clay as obtained in its raw form without any modification on it.

\section{Preparation of Adsorbate (AR Dye Stock Solution)}

Acid red 88 (Figure 2) was used in this study as an adsorbate. Acid red 88 stock solution of $5000 \mathrm{mg} / \mathrm{L}$ was prepared by dissolving $0.5 \mathrm{~g}$ of the dye into $1000 \mathrm{ml}$ distilled water. Subsequent dilutions followed this to prepare the appropriate concentrations as required using distilled water. $\mathrm{pH}$ was adjusted by adding $1 \mathrm{M} \mathrm{NaOH}$ solution and $1 \mathrm{M}$ $\mathrm{HCl}$ acid solution.

Figure 2: Chemical structure of Acid red 88

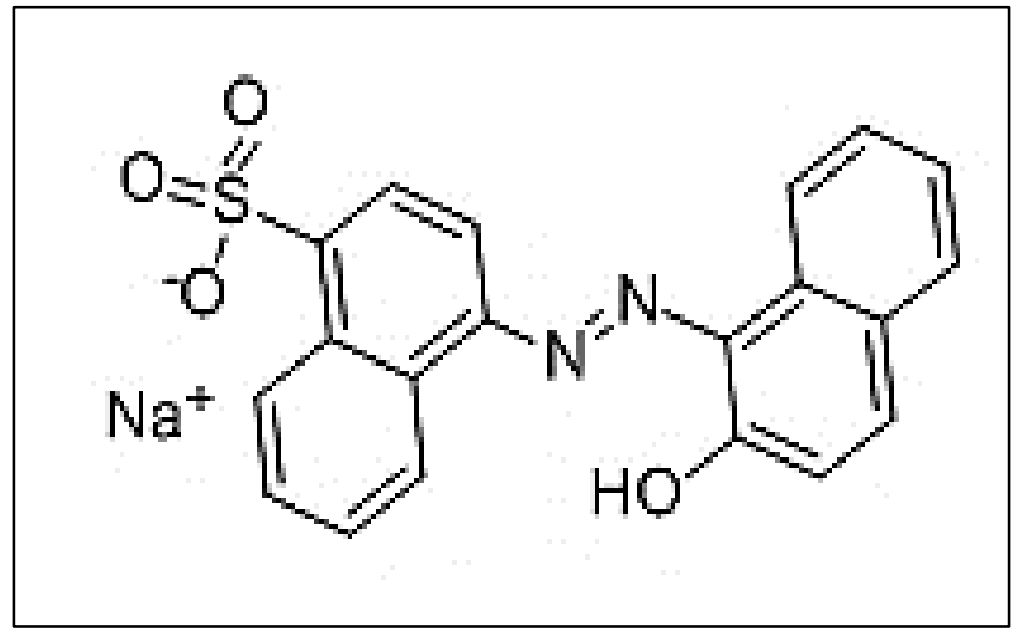

\section{Adsorption Experiment}

Batch adsorption experiments were performed in $250 \mathrm{ml}$ beakers at a stirring rate of $150 \mathrm{rpm}$ and room temperature of $25^{\circ} \mathrm{C}$. A one factor at a time (OFAT) statistical method was used to study the effect of operational parameters of adsorbent dosage, initial dye concentration, $\mathrm{pH}$, and contact time on the removal of AR dye from aqueous solution within a time interval of 60 mins.

In the first experiment, the adsorbent dosage was adjusted from 1 to $28 \mathrm{~g} / \mathrm{L}$ at the $\mathrm{pH}$ of 4.5 and initial dye concentration $(\mathrm{Co}) 100 \mathrm{mg} / \mathrm{L}$. In the second experiment, the aqueous solution $\mathrm{pH}$ was varied between 2 to10 at an adsorbent dosage of $20 \mathrm{~g} / \mathrm{L}$ (optimum from the first experiment), and initial concentration $=100 \mathrm{mg} / \mathrm{L}$. The third experiment was conducted by varying the contact time from 0 -
60 mins at the optimum $\mathrm{pH}$ and adsorbent dosage as obtained from preceding experiments. The fourth experiment was carried out by varying the contact initial AR dye concentration from $100-500 \mathrm{mgL}^{-1}$ as adopted by Akar and Uysal (2010) at the optimum $\mathrm{pH}$, adsorbent dosage, and contact as obtained from earlier experiments. Each time, $100 \mathrm{ml}$ AR dye wastewater sample was subjected to continuous mixing using a magnetic stirrer. The adsorbent was separated from the solution by centrifugation at $6000 \mathrm{~min}^{-1}$ for 10 minutes.

\section{Analytical Methods}

The absorbance of AR solution was measured using a JASCO V-630 UV-visible spectrophotometer (Tokyo, Japan) at a wavelength $\lambda_{\max }=450 \mathrm{~nm}$. The concentration of AR dye was obtained through a calibration curve describing a relationship between

$60 \mid$ This work is licensed under a Creative Commons Attribution 4.0 International License. 
solution concentration $\left(10-50 \mathrm{mgL}^{-1}\right)$ and absorbance of AR (Figure 3). The final concentration
0.2643) from the calibration curve. The $\mathrm{pH}$ was measured using a digital $\mathrm{pH}$ meter JENWAY 370 (Shanghai, China).

was estimated using the equation $(y=0.0376 \mathrm{x}+$

Figure 3: Calibration curve for Acid red 88 dye

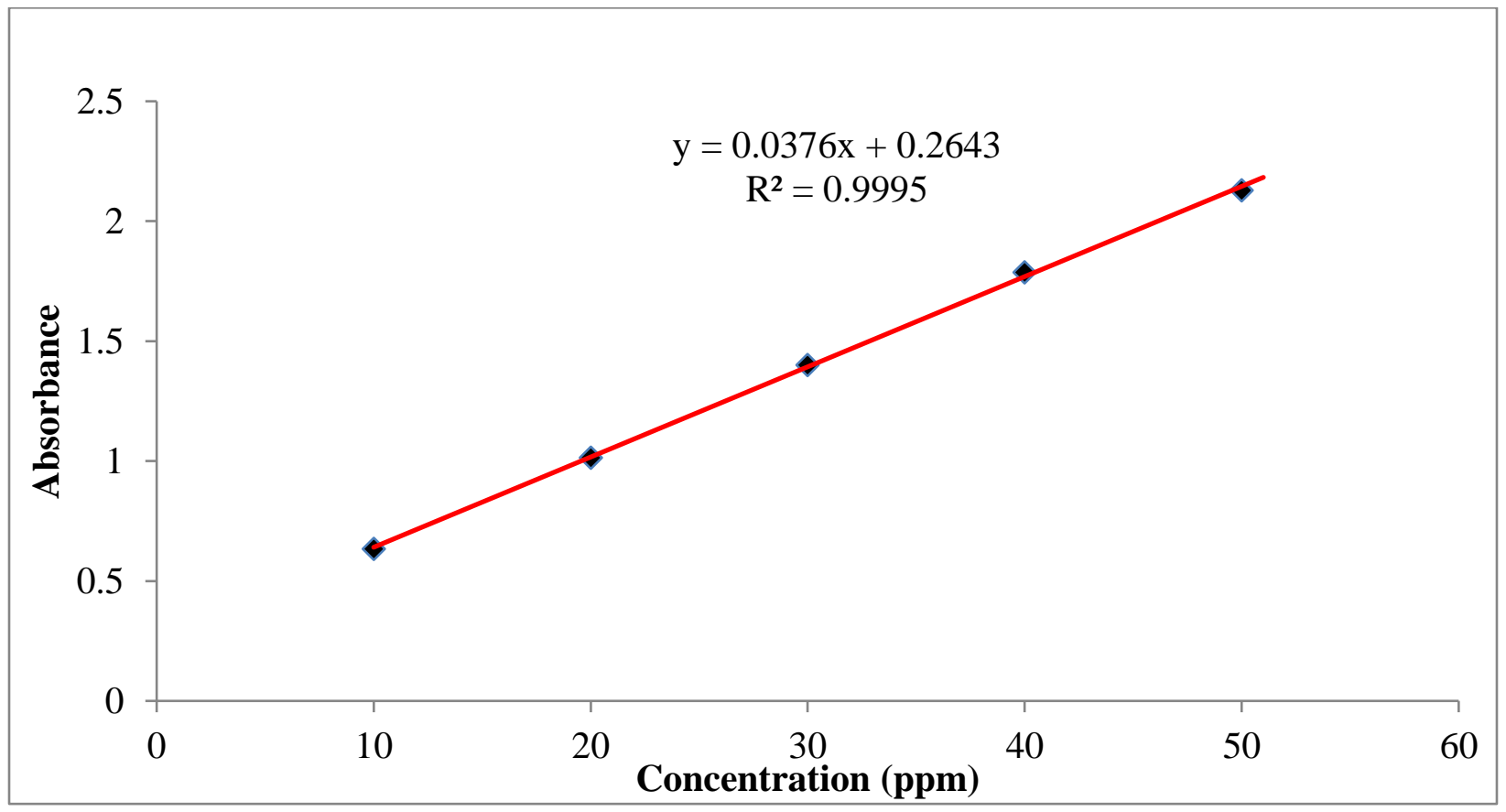

The adsorption figures were used to estimate the AR removal efficiencies (Equation 1) and the adsorption capacities of clay (Equation 2).

$\boldsymbol{E}=\frac{\left(C_{i}-C_{e}\right)}{C_{i}} \times 100 \%$

2020)

$\boldsymbol{q}_{\boldsymbol{e}}=\frac{V\left(C_{i}-C_{e}\right)}{m}$

2021)

Where $\mathbf{E}$ is the removal efficiency; $\mathbf{q}_{\mathbf{e}}$ is equilibrium adsorption capacity and it represents the quantity of dye per unit mass of adsorbent $\left(\mathrm{mg} \cdot \mathrm{g}^{-1}\right) ; \mathrm{C}_{\mathrm{i}}$ and $\mathrm{C}_{\mathrm{e}}$ are the initial and equilibrium concentration of $\mathrm{AR}$ dye in the solutions respectively $(\mathrm{mg} / \mathrm{L})$; $\mathrm{V}$ is the solution volume (L); and $\mathrm{m}$ is the amount of adsorbent (g).

\section{RESULTS AND DISCUSSION}

This section explains in detail the outcomes of the studied clay adsorbent towards its ability to remove AR dye from an aqueous solution. Additionally, the chapter discusses the effect of $\mathrm{pH}$, adsorbent dosage, initial dye concentration and contact time on the performance of clay as an adsorbent.

\section{Effect of Adsorbent Dosage}

The effect of adsorbent dosage was examined in order to establish the optimum dosage. The effect of adsorbent dose was studied by $100 \mathrm{~mL}$ of $\mathrm{AR}$ concentrations $100 \mathrm{mgL}^{-1}$ under different adsorbent doses $(1,2,4,6,8,10,12,14,16,18,20,22,24,26$, and $28 \mathrm{~g}$ ) at a $\mathrm{pH}$ of 4.5 .

AR dye removal efficiency (Figure 4a) was significantly improved from 12.9 to $89.5 \%$ with increasing clay dosage from 1 to $20 \mathrm{~g} / \mathrm{L}$,

61 This work is licensed under a Creative Commons Attribution 4.0 International License. 
respectively $(\mathrm{r} 0.9826, \mathrm{p}<0.05)$. This increase is due to the increased mass of adsorbents resulting into an increased total number of active sites (Kumi et al., 2020). The increase in clay dosage from 20 to $28 \mathrm{~g} / \mathrm{L}$ attained an insignificant improvement in dye adsorption efficiency ( $\mathrm{r}$ 0.7925, p 0.109827). Beyond a saturation adsorbent dosage $(20 \mathrm{~g} / \mathrm{L})$, the available number of AR dye molecules in solution was not enough to completely combine with all effective adsorption sites on the clay, resulting in a surface equilibrium state and a reduction in the adsorption capacity per unit mass of adsorbent. This behaviour could be because any extra addition of adsorbent dosage beyond the optimum value causes an overlapping of adsorption sites, leading to the deficient use of functional groups (Fawzy et al., 2018). However, the adsorption capacity (Figure 4b) had negative correlation ( $\mathrm{r}-0.872733$, $\mathrm{p}<0.05)$ with the adsorbent dose, which could be because some of the adsorption pores remained unoccupied during the adsorption process (Kuang et al., 2020). Accordingly, clay dosage of $20 \mathrm{~g} / \mathrm{L}$ was chosen for further studies.

\section{Figure 4: Effect of adsorbent dosage}

(a)

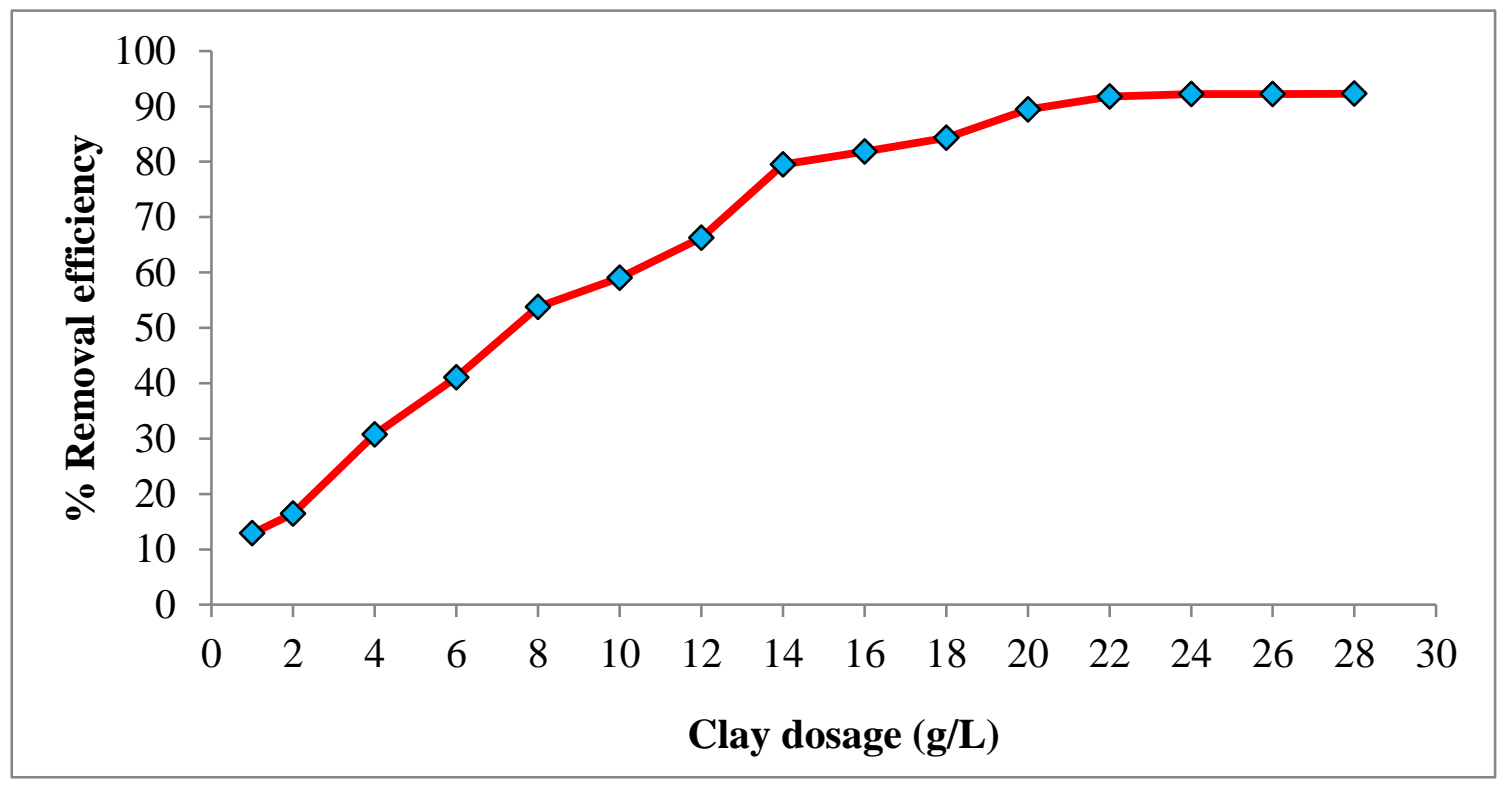

62 | This work is licensed under a Creative Commons Attribution 4.0 International License. 
(b)

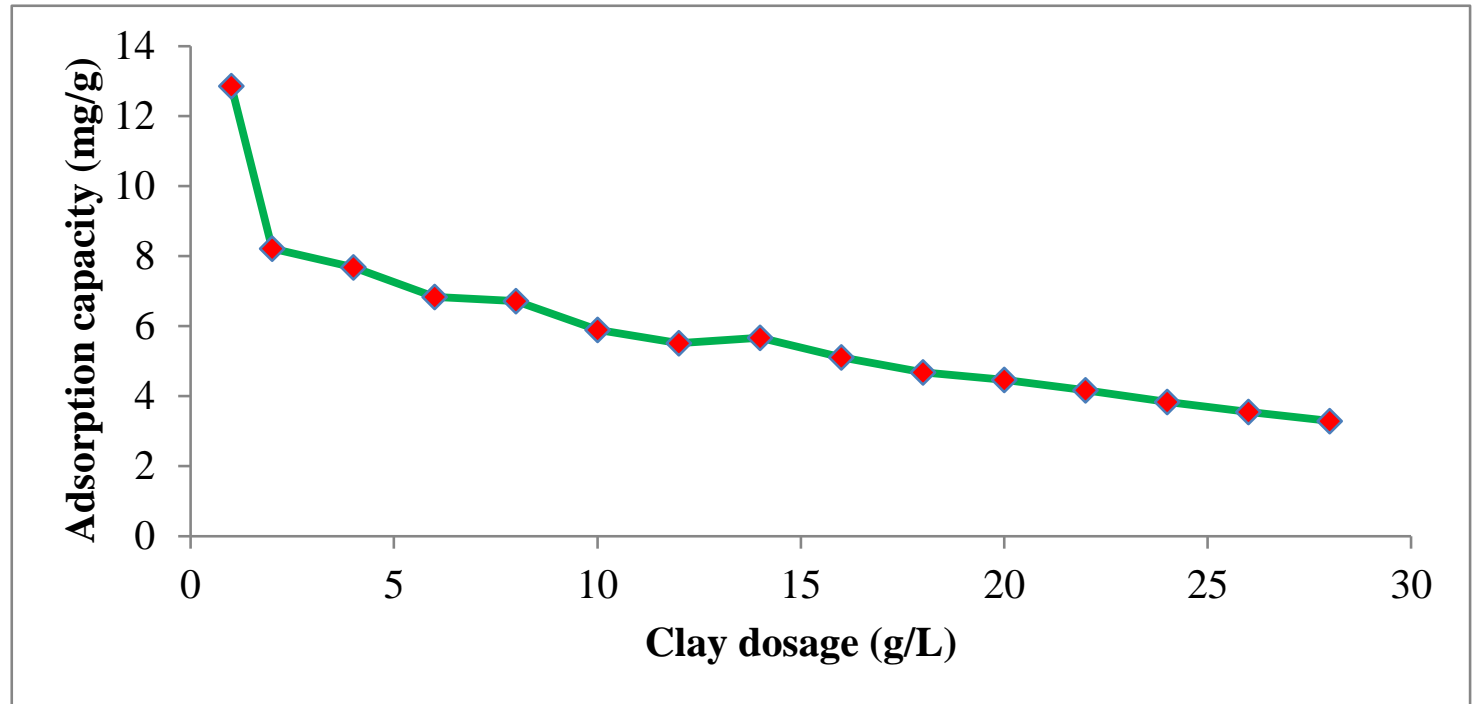

$p H=4$, initial dye concentration $=100 \mathrm{mgL}^{-1}$, contact time $=60 \mathrm{~min}$, mixing speed $\left.=150 \mathrm{rpm}\right)(\boldsymbol{a})$

The \% removal efficiency; $(\boldsymbol{b})$ the adsorption capacity

\section{Effect of Solution pH}

The $\mathrm{pH}$ of a Solution is one of the important parameters governing the adsorption performance of a given adsorbent (Akar \& Uysal, 2010). The variation in Acid red dye percentage removal efficiency of clay is shown in Figure 5.

Figure 5: Effect of solution pH on Acid red dye removal efficiency

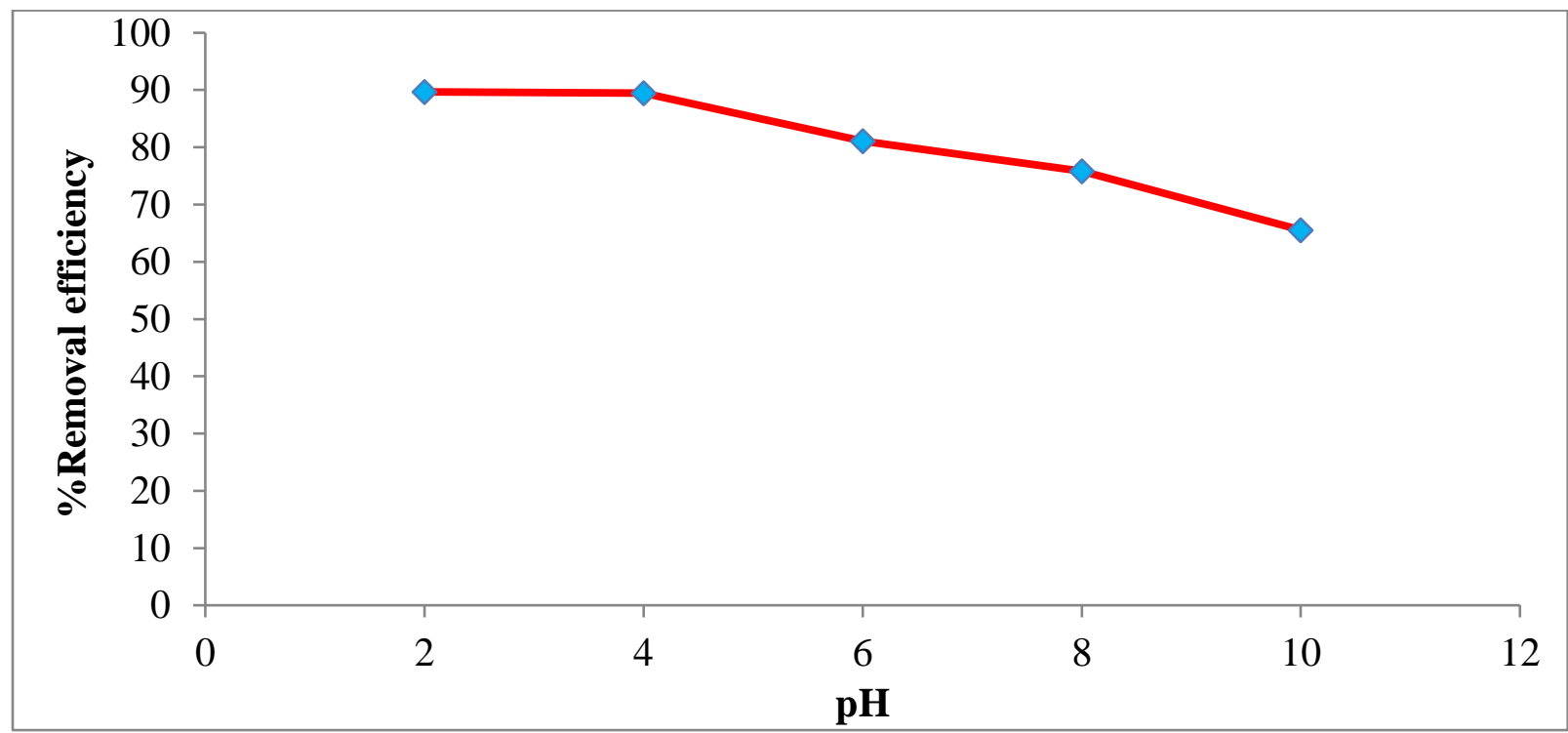

$\left(\right.$ Adsorbent dosage $20 \mathrm{~g} / \mathrm{L}$, initial dye concentration $=100 \mathrm{mgL}^{-1}$, contact time $=60 \mathrm{~min}$, mixing speed $=150$ rpm)

63 This work is licensed under a Creative Commons Attribution 4.0 International License. 
The acid dye removal efficiency was observed to decrease notably with increasing $\mathrm{pH}$. The removal efficiency decreased from $89.7 \%$ to behaviour 65.6 $\%$ with increasing $\mathrm{pH}$ values from 2.0 to 10.0 respectively ( $\mathrm{r}-0.9666$, p 0.007297). However, insignificant removal efficiency was observed with an increase in the $\mathrm{pH}$ from 2 to 4 ( $\mathrm{p} 0.32025)$. High adsorption capacity observed in the acidic $\mathrm{pH}$ values (prevailing of $\mathrm{H}^{+}$ions) could be due to the electrostatic attraction forces between dye anions and positively charged parts on the clay surface.

The abundant presence of $\mathrm{OH}^{-}$ions in basic solution due to an increase in $\mathrm{pH}$ can be competitive for available active sites with the dye anions for effective adsorption (Zhu et al., 2010). Chen \& Zhao (2009) observed that negatively charged surface site on the clay does not favour the adsorption of anionic dye due to electrostatic repulsion. Accordingly, an optimum $\mathrm{pH}$ of 2 was adopted for subsequent experimental work.

\section{Effect of Contact Time}

Figure 6(a) shows the variation removal efficiency with contact time while Figure $6(b)$ shows the variation of adsorption capacity of AR on clay with contact time. AR dye adsorption efficiency significantly increased to $77.6 \%$ in the first 10 minutes of agitation ( $\mathrm{r}$ 0.9821, p 0.000683). However, a relatively constant removal performance was observed with an incremental increase in the contact time above 30 minutes $(r$ 0.8779, p 0.317806).

\section{Figure 6: Effect of contact time}

(a)

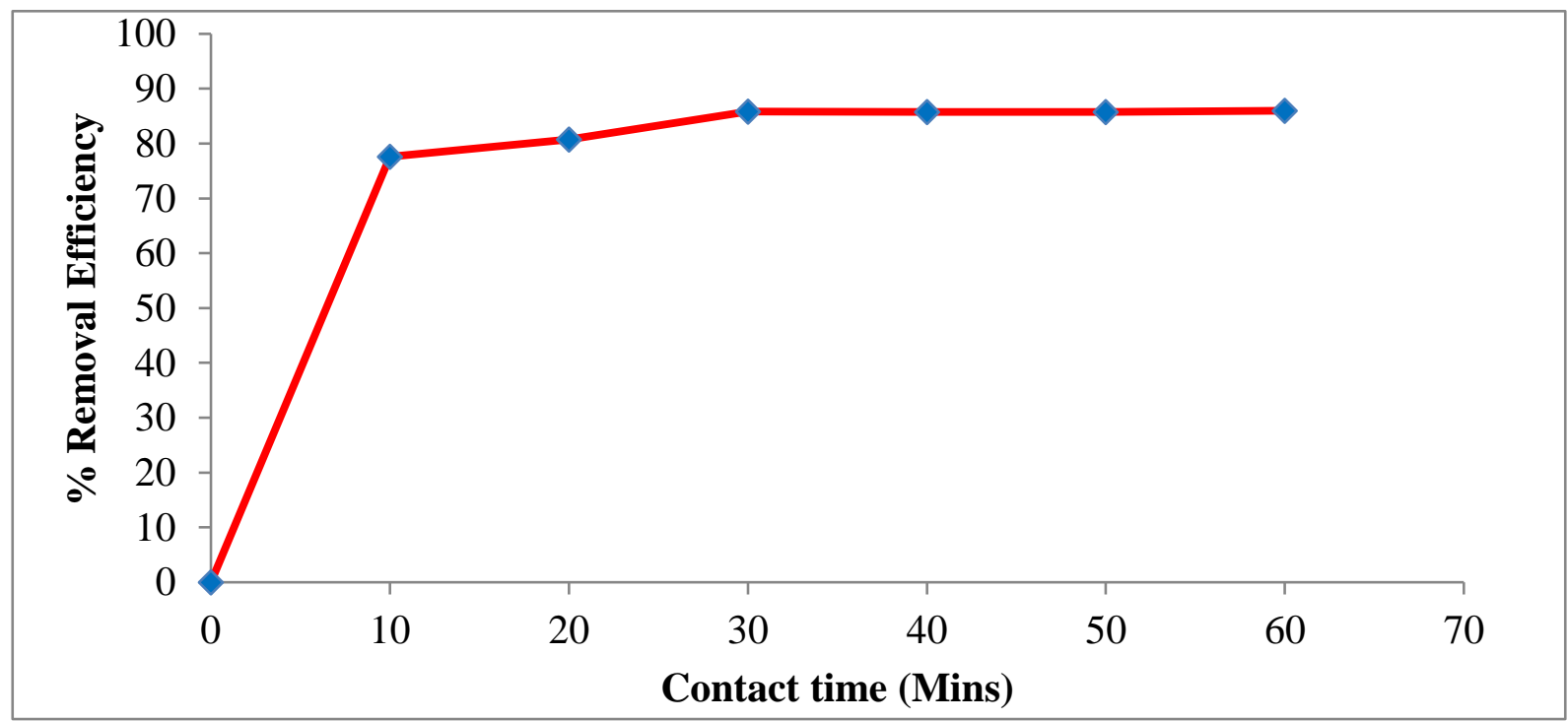

64 | This work is licensed under a Creative Commons Attribution 4.0 International License. 
(b)

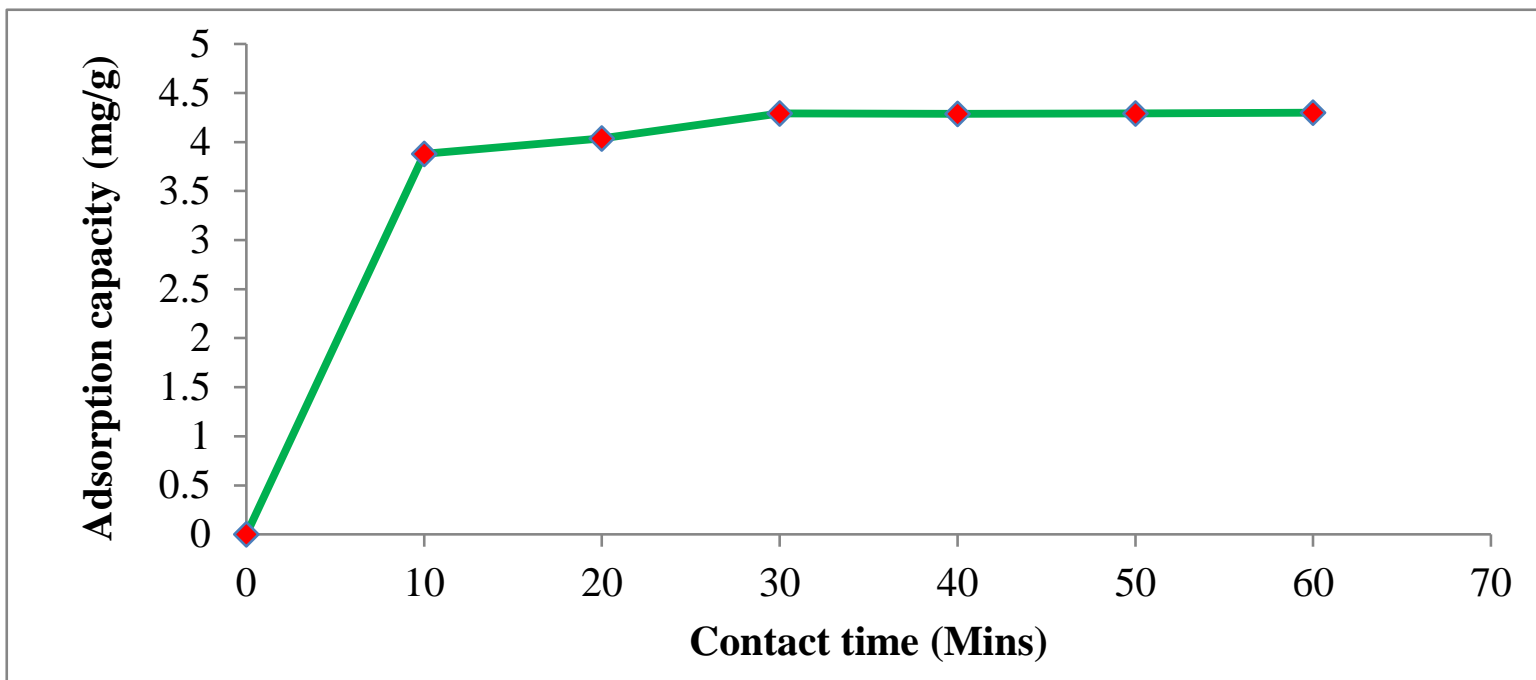

(Adsorbent dosage 20g/L, initial dye concentration $=100 \mathrm{mLL}^{-1}$, mixing speed $\left.=150 \mathrm{rpm}, \mathrm{pH}=2\right)$. (a) The \% removal efficiency; $(b)$ the adsorption capacity

In the initial stages, the high number of unoccupied sites results into a rise in the concentration gradient between the dyes molecules in aqueous solution and that on the clay adsorbent surface. There was no substantial adsorption of AR dye by clay with increasing the agitation time from 30 to $60 \mathrm{~min}$. Thus, the adsorption capacity could be described as a fast-initial rate followed by a slower adsorption rate. The slower adsorption rate could be due to the accumulation of AR molecules on the binding sites at equilibrium, causing saturation of the clay surface (Fawzy et al., 2018).This may also be attributed to the availability of the positively charged surface of the adsorbent which caused rapid electrostatic adsorption of anionic dye AR from the solution at a pH of 2 (Khan, 2020). Similarly, Akar and Uysal (2010) found that untreated clay achieved $98.10 \pm$ $0.34 \%$ removal efficiency of AR 88 dye within 15 min at $\mathrm{pH} 2.0$ in the batch mode.

\section{Effect of Initial AR Dye Concentration $\left(C_{0}\right)$}

The effect of different initial dye concentrations $\left(100,200,300,400,500 \mathrm{mgL}^{-1}\right)$ on the \% removal efficiency and adsorption capacity was studied using the same mass of clay (20g), dye solution $\mathrm{pH}$ of 2, and mixing speed $150 \mathrm{rpm})$. As shown in Figure $7(a)$, the AR dye removal efficiency substantially decreased from 87.5 to $32.4 \%$ with increasing initial concentration $\left(\mathrm{C}_{\mathrm{o}}\right)$ from 100 to 500 $\mathrm{mg} / \mathrm{L}$, respectively ( $\mathrm{r}-0.9168$, p 0.02844). This result indicated that $\mathrm{AR}$ dye molecules were hardly removed at high initial concentrations. At low $\mathrm{C}_{\mathrm{o}}$, the ratio of the available binding sites to the adsorbate molecules was high, enabling the interaction of AR molecules with the clay surface thus achieving high removal efficiency. On the contrary, the decrease in removal efficiency at high initial concentration could be attributed to the lack of sufficient adsorption sites to accommodate further dye molecules present in the aqueous solution (Kabir et al., 2019).

Similarly, the adsorption capacity of clay significantly increased from 4.38 to $8.09 \mathrm{mg} / \mathrm{g}$ when the initial concentration was raised from 100 to 500 $\mathrm{mg} / \mathrm{L}$, respectively (r 0.9168, p 0.02844) as shown in Figure 7(b). An increase in the diffusion of dye in the aqueous solution results into successive collisions between the dye molecules and clay particles (Kumi et al., 2020). 
Figure 7: Effect of dye initial concentration

(a)

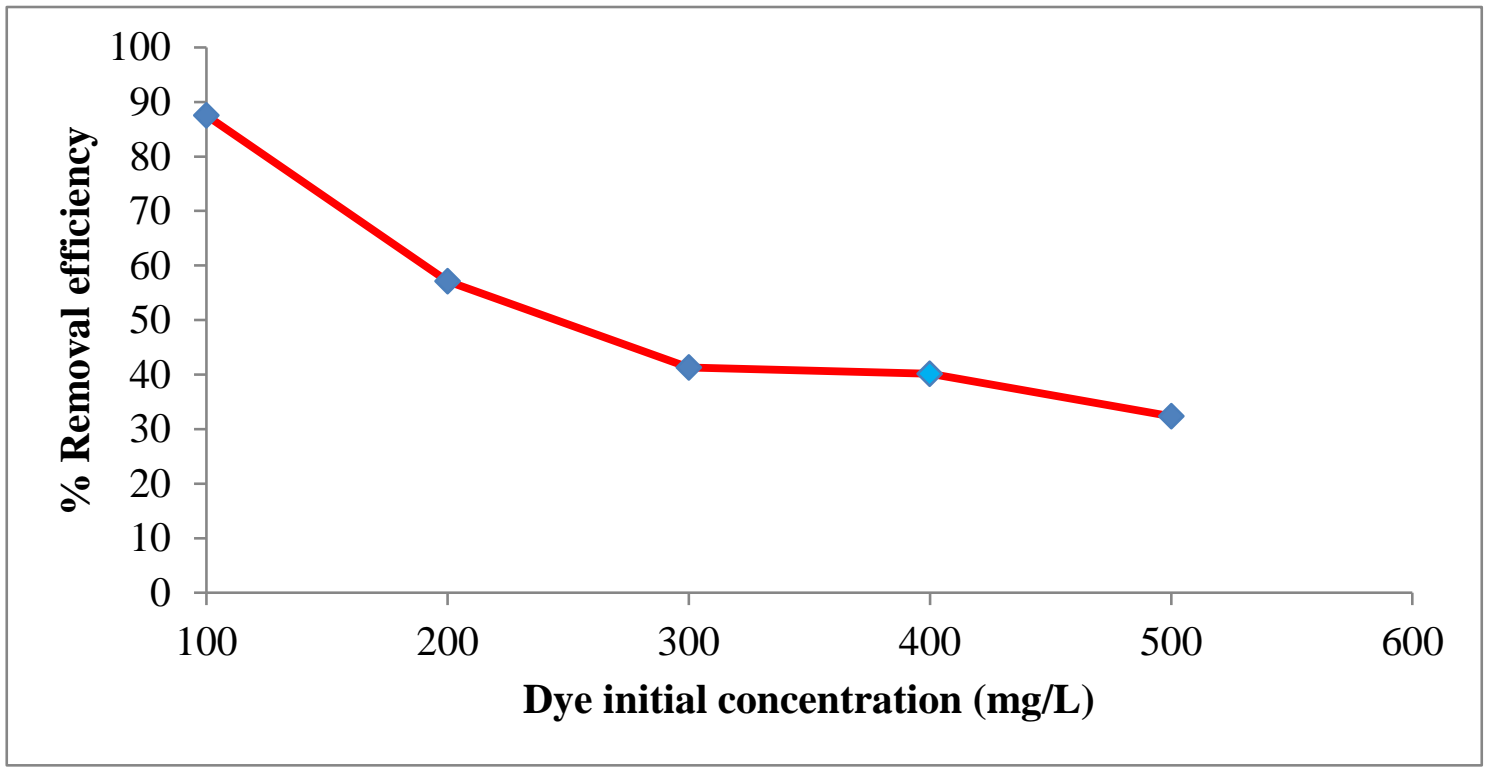

(b)

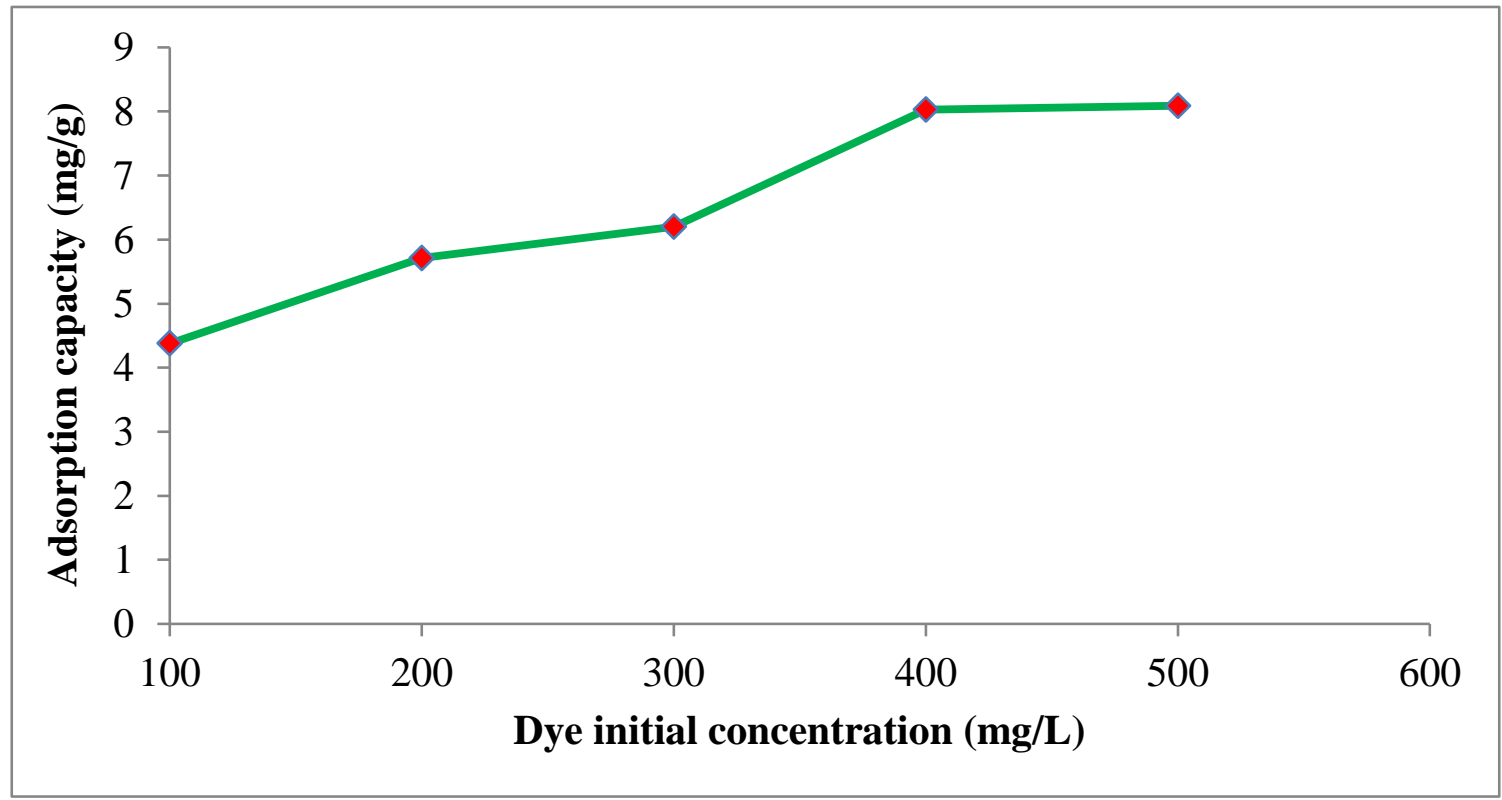

(Adsorbent dosage 20g/L contact time $=30 \mathrm{~min}$, mixing speed $=150 \mathrm{rpm}, \mathrm{pH}=2)$. (a) The \% removal efficiency; (b) the adsorption capacity

Performance Evaluation of Clay in the Acid Red Dye Removal
To evaluate the performance of clay as an adsorbent for the treatment of industrial wastewater with AR 88 dye colorization, the results obtained from this study were compared to the performance of other

66 This work is licensed under a Creative Commons Attribution 4.0 International License. 
adsorbents (Calcined alunite, raw alunite, lemna minor biomass, magnetic graphene oxide/cationic hydrogel nanocomposite, porous biochar-supported Fe-Mn composite and persulfate (PS), saw dust, polyamine-modified magnetic graphene oxide, graphene nanosheet, and chitosanpolyethyleneimine synthesized with calcium chloride).

Table 1: Comparison of various adsorbents for AR 88 dye removal

\begin{tabular}{|c|c|c|c|c|}
\hline Adsorbent & Efficiency (\%) & Dosage $(g / L)$ & pH & Reference \\
\hline $\begin{array}{l}\text { Porous biochar-supported Fe-Mn } \\
\text { composite and persulfate (PS) }\end{array}$ & 98.84 & $\begin{array}{l}\mathrm{Fe}-\mathrm{Mn} / \mathrm{BC}=1 \\
\mathrm{PS}=2\end{array}$ & 2 & (Chen et al., 2020) \\
\hline $\begin{array}{l}\text { Polyamine-modified magnetic } \\
\text { graphene oxide }\end{array}$ & 73 & 1 & 3 & (Abdi et al., 2019) \\
\hline Calcined Alunite & 98 & 0.2 & 2 & $\begin{array}{l}\text { (Tunali Akar et al., } \\
\text { 2013) }\end{array}$ \\
\hline Raw alunite & 93 & 0.3 & 2 & $\begin{array}{l}\text { (Tunali Akar et al., } \\
\text { 2013) }\end{array}$ \\
\hline Lemna minor biomass & 98 & 6 & 3 & (Balarak et al., 2015) \\
\hline $\begin{array}{l}\text { Magnetic graphene oxide/hydrogel } \\
\text { nanocomposite }\end{array}$ & 95 & 0.3 & 3 & (Dong and Wang, 2016) \\
\hline Saw dust & 84.46 & 30 & 3 & $\begin{array}{l}\text { (Modirshahla et al., } \\
\text { 2010) }\end{array}$ \\
\hline Graphene nanosheet & 84.5 & 30 & 3 & $\begin{array}{l}\text { (Modirshahla et al., } \\
\text { 2010) }\end{array}$ \\
\hline $\begin{array}{l}\text { Chitosan-polyethyleneimine } \\
\text { synthesized with calcium chloride }\end{array}$ & 87.9 & 0.4 & 3 & (Yusof et al., 2020) \\
\hline Clay & 89.7 & 20 & 2 & This study \\
\hline
\end{tabular}

The results for each of the respective materials are summarized in table 1, showing the removal efficiency of the AR dye at optimum condition of dosage and $\mathrm{pH}$. The clay adsorbent shows a higher AR dye removal efficiency than saw dust, polyamine-modified magnetic graphene oxide, graphene nanosheet, and chitosanpolyethyleneimine synthesized with calcium chloride and comparable to raw alunite and magnetic graphene oxide/cationic hydrogel nanocomposite. It can thus be construed that the performance of clay is satisfactory and comparable with other alternative adsorbents.

\section{CONCLUSION}

Clay adsorbent can effectively achieve a good performance removal of AR dye from wastewater minus any surface modification. This study indicated that the adsorption process of AR as an adsorbate and clay as an adsorbent is largely influenced by initial $\mathrm{pH}$, adsorbent dosage, initial dye concentration, and contact time. The removal efficiency decreased with increase in the initial dye concentration. Also, the adsorption was found to be higher for lower $\mathrm{pH}$ and the optimum $\mathrm{pH}$ for the aqueous solution was 2 , achieving AR dye removal efficiency of $87.5 \%$ under initial concentration $100 \mathrm{mg} / \mathrm{L}$, clay dosage $20 \mathrm{~g} / \mathrm{L}$, mixing speed of 150 $\mathrm{rpm}$, and equilibrium time of 30 minutes. Therefore, it may be concluded that this cheap and environment friendly clay can be used as a replacement to highcost conventional commercial adsorbents including activated carbon, silica gel, zeolites, and polymeric organic resins.

$67 \mid$ This work is licensed under a Creative Commons Attribution 4.0 International License. 


\section{REFERENCES}

Abdi, G., Alizadeh, A., Amirian, J., Rezaei, S., \& Sharma, G. (2019). Polyamine-modified magnetic graphene oxide surface: feasible adsorbent for removal of dyes. Journal of Molecular Liquids, 289, 111118.

AbdurRahman, F. B., Akter, M., \& Abedin, M. Z. (2013). Dyes removal from textile wastewater using orange peels. International journal of scientific \& technology research, 2(9), 47-50.

Afanga, H., Zazou, H., Titchou, F. E., Rakhila, Y., Akbour, R. A., Elmchaouri, A., Ghanbaja, J., \& Hamdani, M. (2020). Integrated electrochemical processes for textile industry wastewater treatment: system performances and sludge settling characteristics. Sustainable Environment Research, 30(1), 1-11.

Akar, S. T., \& Uysal, R. (2010). Untreated clay with high adsorption capacity for effective removal of CI Acid Red 88 from aqueous solutions: batch and dynamic flow mode studies. Chemical Engineering Journal, 162(2), 591-598.

Almoisheer, N., Alseroury, F. A., Kumar, R., Almeelbi, T., \& Barakat, M. A. (2019). Synthesis of graphene oxide/silica/carbon nanotubes composite for removal of dyes from wastewater. Earth Systems and Environment, 3(3), 651-659.

Badvi, K., \& Javanbakht, V. (2021). Enhanced photocatalytic degradation of dye contaminants with TiO2 immobilized on ZSM-5 zeolite modified with nickel nanoparticles. Journal of Cleaner Production, 280, 124518.

Balarak, D., Pirdadeh, F., \& Mahdavi, Y. (2015). Biosorption of Acid Red 88 dyes using dried Lemna minor biomass. Journal of Science, Technology \& Environment Informatics, 1(02), 81-90.
Belachew, N., \& Bekele, G. (2020). Synergy of magnetite intercalated bentonite for enhanced adsorption of congo red dye. Silicon, 12(3), 603612.

Bhatti, H. N., Safa, Y., Yakout, S. M., Shair, O. H., Iqbal, M., \& Nazir, A. (2020). Efficient removal of dyes using carboxymethyl cellulose/alginate/polyvinyl alcohol/rice husk composite: adsorption/desorption, kinetics and recycling studies. International journal of biological macromolecules, 150, 861-870.

Chaker, H., Ameur, N., Saidi-Bendahou, K., Djennas, M., \& Fourmentin, S. (2021). Modeling and Box-Behnken design optimization of photocatalytic parameters for efficient removal of dye by lanthanum-doped mesoporous TiO2. Journal of Environmental Chemical Engineering, 9(1), 104584.

Chen, H., \& Zhao, J. (2009). Adsorption study for removal of Congo red anionic dye using organoattapulgite. Adsorption, 15(4), 381-389.

Chen, L., Jiang, X., Xie, R., Zhang, Y., Jin, Y., \& Jiang, W. (2020). A novel porous biocharsupported Fe-Mn composite as a persulfate activator for the removal of acid red 88. Separation and Purification Technology, 250, 117232.

Dikmen, S., Gunay, A., Ersoy, B., \& Erol, I. (2015). Determination of equilibrium, kinetic and thermodynamic parameters of acid red 88 adsorption onto montmorillonitic clay. Environmental Engineering and Management Journal, 14(5), 1097-1110.

Dong, S., \& Wang, Y. (2016). Removal of acid red 88 by a magnetic graphene oxide/cationic hydrogel nanocomposite from aqueous solutions: Adsorption behaviour and mechanism. RSC Advances, 6(68), 6392263932.

68 This work is licensed under a Creative Commons Attribution 4.0 International License. 
Fawzy, M., Nasr, M., Nagy, H., \& Helmi, S. (2018). Artificial intelligence and regression analysis for Cd (II) ion biosorption from aqueous solution by Gossypium barbadense waste. Environmental Science and Pollution Research, 25(6), 58755888.

Feng, Q., Gao, B., Yue, Q., \& Guo, K. (2021). Flocculation performance of papermaking sludge-based flocculants in different dye wastewater treatment: Comparison with commercial lignin and coagulants. Chemosphere, 262, 128416.

Gholizadeh, A. M., Zarei, M., Ebratkhahan, M., Hasanzadeh, A., \& Vafaei, F. (2020). Removal of Phenazopyridine from wastewater by merging biological and electrochemical methods via Azolla filiculoides and electro-Fenton process. Journal of Environmental Management, 254, 109802.

Hasan, M. M., Shenashen, M. A., Hasan, M. N., Znad, H., Salman, M. S., \& Awual, M. R. (2021). Natural biodegradable polymeric bioadsorbents for efficient cationic dye encapsulation from wastewater. Journal of Molecular Liquids, 323, 114587.

Joseph, J., Radhakrishnan, R. C., Johnson, J. K., Joy, S. P., \& Thomas, J. (2020). Ion-exchange mediated removal of cationic dye-stuffs from water using ammonium phosphomolybdate. Materials Chemistry and Physics, 242, 122488.

Kabir, S. M., Cueto, R., Balamurugan, S., Romeo, L. D., Kuttruff, J. T., Marx, B. D., \& Negulescu, I. I. (2019). Removal of acid dyes from textile wastewaters using fish scales by absorption process. Clean Technologies, 1(1), 311-324.

Khan, M. I. (2020). Adsorption of methylene blue onto natural Saudi Red Clay: isotherms, kinetics and thermodynamic studies. Materials Research Express, 7(5), 055507.
Kuang, Y., Zhang, X., \& Zhou, S. (2020). Adsorption of methylene blue in water onto activated carbon by surfactant modification. Water, 12(2), 587.

Kumi, A. G., Ibrahim, M. G., Fujii, M., \& Nasr, M. (2020). Synthesis of sludge-derived biochar modified with eggshell waste for monoethylene glycol removal from aqueous solutions. $S N$ Applied Sciences, 2(10), 1-12.

Li, P., Gao, B., Li, A., \& Yang, H. (2020). Evaluation of the selective adsorption of silicasand/anionized-starch composite for removal of dyes and Cupper (II) from their aqueous mixtures. International Journal of Biological Macromolecules, 149, 1285-1293.

Liu, H., Zhang, J., Lu, M., Liang, L., Zhang, H., \& Wei, J. (2020). Biosynthesis based membrane filtration coupled with iron nanoparticles reduction process in removal of dyes. Chemical Engineering Journal, 387, 124202.

Liu, Q., Li, Y., Chen, H., Lu, J., Yu, G., Möslang, M., \& Zhou, Y. (2020). Superior adsorption capacity of functionalised straw adsorbent for dyes and heavy-metal ions. Journal of Hazardous Materials, 382, 121040.

Mcyotto, F., Wei, Q., Macharia, D. K., Huang, M., Shen, C., \& Chow, C. W. (2021). Effect of dye structure on colour removal efficiency by coagulation. Chemical

Engineering Journal, 405, 126674.

Melnyk, I. V., Tomina, V. V., Stolyarchuk, N. V., Seisenbaeva, G. A., \& Kessler, V. G. (2021). Organic dyes (acid red, fluorescein, methylene blue) and copper (II) adsorption on amino silica spherical particles with tailored surface hydrophobicity and porosity. Journal of Molecular Liquids, 336, 116301.

Modirshahla, N., \& Behnajady, M., \& Shamel, A., \& Eskandari, H. (2010). Sorption Study of C.I.

69 | This work is licensed under a Creative Commons Attribution 4.0 International License. 
Acid Red 88 From Aqueous Solutions onto Sawdust. Journal of Physical and Theoretical Chemistry, 7(2), 77-81.

Mukhlish, M. B., Khan, M. R., Islam, M. S., Nazir, M. I., Snigdha, J. S., Akter, R., \& Ahmad, H. (2020). Decolorization of Reactive Dyes from Aqueous Solution Using Combined Coagulation-Flocculation and Photochemical Oxidation $\left(\mathrm{UV} / \mathrm{H}_{2} \mathrm{O}_{2}\right)$. Sustainable Chemical Engineering, 51-61.

Munjur, H. M., Hasan, M. N., Awual, M. R., Islam, M. M., Shenashen, M. A., \& Iqbal, J. (2020). Biodegradable natural carbohydrate polymeric sustainable adsorbents for efficient toxic dye removal from wastewater. Journal of Molecular Liquids, 319, 114356.

Paz, A., Carballo, J., Pérez, M. J., \& Domínguez, J. M. (2017). Biological treatment of model dyes and textile wastewaters. Chemosphere, 181, 168-177.

Saad, M. S., Balasubramaniam, L., Wirzal, M. D. H., Abd Halim, N. S., Bilad, M. R., Md Nordin, N. A. H., ... \& Ramli, F. N. (2020). Integrated Membrane-Electrocoagulation System for Removal of Celestine Blue Dyes in Wastewater. Membranes, 10(8), 184.

Semiz, L. (2020). Removal of reactive black 5 from wastewater by membrane filtration. Polymer Bulletin, 77(6), 3047-3059.

Sharma, A., Syed, Z., Brighu, U., Gupta, A. B., \& Ram, C. (2019). Adsorption of textile wastewater on alkali-activated sand. Journal of cleaner production, 220, 23-32.

Shoukat, R., Khan, S. J., \& Jamal, Y. (2019). Hybrid anaerobic-aerobic biological treatment for real textile wastewater. Journal of Water Process Engineering, 29, 100804.

Singh, H., Chauhan, G., Jain, A. K., \& Sharma, S. K. (2017). Adsorptive potential of agricultural wastes for removal of dyes from aqueous solutions. Journal of Environmental Chemical Engineering, 5(1), 122-135.

Sirajudheen, P., Karthikeyan, P., Vigneshwaran, S., \& Meenakshi, S. (2020). Synthesis and characterization of La (III) supported carboxymethylcellulose-clay composite for toxic dyes removal: Evaluation of adsorption kinetics, isotherms and thermodynamics. International journal of biological macromolecules, 161, 1117-1126.

Sarkar, K., Banerjee, S. L., \& Kundu, P. P. (2012). Removal of anionic dye in acid solution by self crosslinked insoluble dendronized chitosan. Hydrol Current Res, 3(133), 2.

Suganya, S., Saravanan, A., \& Ravikumar, C. (2017). Computation of adsorption parameters for the removal of dye from wastewater by microwave assisted sawdust: theoretical and experimental analysis. Environmental Toxicology and Pharmacology, 50, 45-57.

Thirumoorthy, K., \& Krishna, S. K. (2020). Removal of cationic and anionic dyes from aqueous phase by Ball clay-Manganese dioxide nanocomposites. Journal of Environmental Chemical Engineering, 8(1), 103582.

Tunali Akar, S., Alp, T., \& Yilmazer, D. (2013). Enhanced adsorption of Acid Red 88 by an excellent adsorbent prepared from alunite. Journal of Chemical Technology \& Biotechnology, 88(2), 293-304.

Wang, J., Yao, J., Wang, L., Xue, Q., Hu, Z., \& Pan, B. (2020). Multivariate optimization of the pulse electrochemical oxidation for treating recalcitrant dye wastewater. Separation and Purification Technology, 230, 115851.

Wang, Q., Liang, L., Tian, G., Mao, Q., \& Meng, X. (2020). Adsorption of azo dye malachite green onto rice wine lees: kinetic and adsorption

70 | This work is licensed under a Creative Commons Attribution 4.0 International License. 
isotherms. Nature Environment and Pollution Technology, 19(2), 563-570.

Wang, S., Gao, H., Fang, L., Hu, Q., Sun, G., Chen, X., Yu, C., Tang, S., Yu, X., Zhao, X., Guangzhuang, S., \& Yang, H. (2021). Synthesis of novel CQDs/CeO2/SrFe12O19 magnetic separation photocatalysts and synergic adsorption-photocatalytic degradation effect for methylene blue dye removal. Chemical Engineering Journal Advances, 6, 100089.

Wang, Y., Geng, Q., Yang, J., Liu, Y., \& Liu, C. (2020). Hybrid System of FlocculationPhotocatalysis for the Decolorization of Crystal Violet, Reactive Red X-3B, and Acid Orange II Dye. ACS Omega, 5(48), 31137-31145.

Xia, L., Zhou, S., Zhang, C., Fu, Z., Wang, A., Zhang, Q., Wang, Y., Liu, X., Wang, X., \& Xu, W. (2020). Environment-friendly Juncus effusus-based adsorbent with a threedimensional network structure for highly efficient removal of dyes from wastewater. Journal of Cleaner Production, 259, 120812.

Yusof, N. H., Foo, K. Y., Hameed, B. H., Hussin, M. H., Lee, H. K., \& Sabar, S. (2020). One-step synthesis of chitosan-polyethyleneimine with calcium chloride as effective adsorbent for Acid Red 88 removal. International journal of biological macromolecules, 157, 648-658.

Zhu, H. Y., Jiang, R., \& Xiao, L. (2010). Adsorption of an anionic azo dye by chitosan $/ \mathrm{kaolin} / \gamma$ Fe2O3 composites. Applied clay science, 48(3), 522-526.

71 This work is licensed under a Creative Commons Attribution 4.0 International License. 